\title{
Experimental Study on Groutability of Sand Layer concerning Permeation Grouting
}

\author{
Yan-Xu Guo, Qing-Song Zhang $\mathbb{D}^{D}$, Lian-Zhen Zhang ${ }^{(D}$, Ren-Tai Liu, Xin Chen, \\ and Yan-Kai Liu \\ Research Center of Geotechnical and Structural Engineering, Shandong University, Jinan 250061, China \\ Correspondence should be addressed to Qing-Song Zhang; zhangqingsong@sdu.edu.cn
}

Received 24 December 2020; Revised 1 March 2021; Accepted 9 March 2021; Published 16 March 2021

Academic Editor: Hamed Akhavan

Copyright (c) 2021 Yan-Xu Guo et al. This is an open access article distributed under the Creative Commons Attribution License, which permits unrestricted use, distribution, and reproduction in any medium, provided the original work is properly cited.

\begin{abstract}
Permeation grouting is widely used in grouting engineering because of its low grouting pressure and minor disturbance to the stratum. However, influenced by the complex properties of sand layer and slurry, an accurate prediction of the groutability of the sand layer remains to be a hard work. In this paper, the permeability of sand layer is studied based on a self-designed permeation grouting test device, which considers the different sand particle size, relative density of sand layer, slurry water-cement ratio, and clay content. The influencing factors of sand layer groutability are analyzed, and the different parameters that affect the grouting of sand layer are evaluated, thus proposing a new approach to predict the groutability of sand layer. Results show that the sand particle size and slurry water-cement ratio are positively related to the groutability of sand layer, and the relative density and clay content of sand layer are negatively correlated with the groutability of sand layer. The proposed alternative empirical formula to estimate the groutability of sand layer will help predict the groutability of sand layer with a higher degree of accuracy, which can provide a certain reference for engineering.
\end{abstract}

\section{Introduction}

With the development of economy and the increasing population, the construction of tunnel subway engineering has developed rapidly [1-6]. However, during the construction of the tunnel and subway, unfavorable geology such as sand layer will be encountered, and the stratum needs to be improved to prevent disasters such as sand inrush and collapse. As one of the most widely used grouting methods, permeation grouting works under low pressure and does not destroy the original structure of the medium to be grouted. In permeation grouting, the slurry is injected into the pore medium to achieve the purpose of reinforcement, water sealing, and seepage prevention [7-9].

When penetrating the medium, whether the grout could be injected into the medium is a prerequisite for penetrating grouting [10]. Therefore, the groutability of a specific medium is the basic property that must be identified in grouting design. Moreover, groutability is the main basis for selecting the grouting material and determining the corresponding grouting process and is of great significance to improve the grouting effect $[11,12]$. At present, the research on the groutability of penetration grouting mainly focuses on two kinds of grouting materials: superfine cement grout and chemical grout. Tekin investigated the permeability of microfine cement (Rheocem 900) into sand specimens with a variety of grain-size distributions and established a formula for predicting the groutability of sand layer $[13,14]$. Considering the water-cement ratio, sand gradation, and relative density, Mollamahmutoglu and Avci experimented on groutability of ultrafine Portland cement $[15,16]$. Markou et al. used microfine cement as the research object to study the influence of sand gradation and water-cement ratio on the groutability of sand layer. On this basis, the relevant prediction model of groutability was established by binary logical regression analysis of the test results $[17,18]$. Ozgurel and Vipulanandan used acrylamide as the grouting material to study the influence of fines content on the groutability of the sand layer [19]. Hassanlourad and Sarrafi investigated the groutability of sodium silicate chemical 
grout into the sand layer by injecting three kinds of sodium silicate chemical grouts with different viscosity into sand specimens of coarse, medium, fine, and silty sand and three kinds of relative density. It is proposed that the particle size is the main factor affecting the groutability [20].

Although scholars have conducted extensive research on the groutability of superfine cement grout and chemical grout, ordinary Portland cement is still the most widely used one in engineering [21-23]. Compared with ordinary Portland cement, chemical grout can permeate a finer sand layer, but it is expensive and poses environmental and health problems. Although superfine cement is not toxic, it is typically three to four times higher than that of ordinary Portland cement, and the price of superfine cement in the U.S.A. is roughly 10 times higher than that of ordinary Portland cement [24]. Therefore, if ordinary Portland cement can meet the requirements of groutability, the engineering cost will be greatly reduced.

However, there are few researches on the prediction of the groutability of ordinary cement in media, and a commonly accepted criterion for determining groutability has not been achieved. First solutions were developed based on grain size of soil and cement only [25-27]. Herndon and Lenahan defined some penetrability limits for grouting materials concerning particle-size distribution of soil [28]. According to this research, the soil cannot be grouted if more than $10 \%$ of the soil particles pass through a No. 200 sieve $(75 \mu \mathrm{m})$. The above standards are only based on the particle size of the grouting material and medium without considering factors such as $W / C$. However, the maximum diameter of the grouting material particles is not the only parameter that controls the permeability of the grouting. Large-scale tests indicated that factors impacting groutability are directly related to the parameters characterizing the properties of soil and slurry [8]. These parameters include the particle size of the slurry, the particle size of the medium to be grouted, relative density, and water-cement ratio (or viscosity) of slurry. For porous media, if GR (groutability ratio, GR $=D_{15} / d_{95}$ ) $\geq$ 25 , it is possible to ensure grouting, and if GR $\leq 11$, the cement slurry cannot be used to grout the soil. If $11 \leq \mathrm{GR} \leq 19$, the cement slurry may not be used to grout the soil [29]. King and Bush held that the GR $\left(\mathrm{GR}=D_{10} / d_{95}\right) \geq 16$ should be satisfied to ensure the success of grouting [30].

It can be known from the researches above that many factors are influencing the groutability, and the groutability of the sand layer is a function related to different parameters such as the particle size of the medium and the grouting material, the fine content of sand layer, the relative density of sand layer, and water-cement ratio, and most of the existing standards only consider one or a few parameters. To further improve the accuracy of prediction, the influence of particle size, density, slurry water-cement ratio, and clay content on the groutability of sand layer is analyzed by the sand penetration grouting simulation test, and the groutability of multiple factors to the sand layer is studied. Based on the analysis of the test results, a new empirical formula to predict the groutability of sand layer is established.

\section{Experimental Procedures}

2.1. Test Apparatus. As shown in Figure 1, the sand penetration grouting simulation test apparatus consists of a power apparatus, a grout storage tank, and a test frame. The principle of the test is to use the gas pressure of the compressed nitrogen as the grouting power to push the grout into the sand layer. A constant grouting pressure should be maintained during the grouting process. The detailed introduction of the test apparatus is shown in reference [31].

\subsection{Test Materials}

2.2.1. Ordinary Portland Cement. The test cement is $42.5 \mathrm{R}$ Portland cement, and the cement quality conforms to the standard of 《Portland cement, ordinary Portland cement》 (GB175-99). The chemical composition of cement is shown in Table 1, the basic physical and mechanical properties of cement are shown in Table 2, and the grain-size distribution curve of the cement used in the test is shown in Figure 2.

The particle-size distribution of ordinary Portland cement used in the test is between $0.4 \mu \mathrm{m}$ and $80 \mu \mathrm{m}$, with a wide range of particle-size distribution. The three characteristic particle sizes of cement are shown in Table 3.

2.2.2. Medium to be Grouted. The medium to be grouted takes quartz sand as the raw material, in which the content of silica $\left(\mathrm{SiO}_{2}\right)$ is more than $96 \%$, the loss on ignition is not more than $0.40 \%$, and the mud content (including soluble salts) is not more than $0.20 \%$.

The medium sample is divided into two groups: Group A is of single particle size; Group B is of mixed particle size. Group A contains 7 samples, and the particle size ranges are $0.08 \sim 0.16 \mathrm{~mm}, \quad 0.16 \sim 0.315 \mathrm{~mm}, \quad 0.315 \sim 0.63 \mathrm{~mm}$, $0.63 \sim 1.25 \mathrm{~mm}, 1.25 \sim 2.5 \mathrm{~mm}, 2.5 \sim 5 \mathrm{~mm}$, and $5 \sim 10 \mathrm{~mm}$, respectively. Group B is a combination of $0.63 \sim 1.25 \mathrm{~mm}$ particle size group and $1.25 \sim 2.5 \mathrm{~mm}$ particle size group in different proportions, including 4 samples. The characteristic particle sizes and other physical parameters of all samples are shown in Table 4, and the grading curve is shown in Figure 3.

2.3. Test Plan. Before the test, the criteria for determining the groutability of the sand layer should be made explicit, which is presented as follows: under the given experimental conditions (grouting pressure: $1 \mathrm{MPa}$; grouting time: $5 \mathrm{~min}$ ), if the slurry can fill up the $10 \mathrm{~cm}$ sand column, it is considered to be successful grouting; if the penetration depth of the slurry in sand layer is less than $1 \mathrm{~cm}$, it is considered to be unsuccessful grouting; if the penetration depth of the slurry is within the range of $1 \sim 10 \mathrm{~cm}$, then it is considered to be insufficient grouting [32].

In order to systematically study the groutability of sand layer, various factors which may affect the groutability of sand layer are fully considered in the test process. The grouting pressure is the main factor to influence grouting diffusing radius, and the groutability is not influenced by grouting pressure. The increase in pressure only increases 


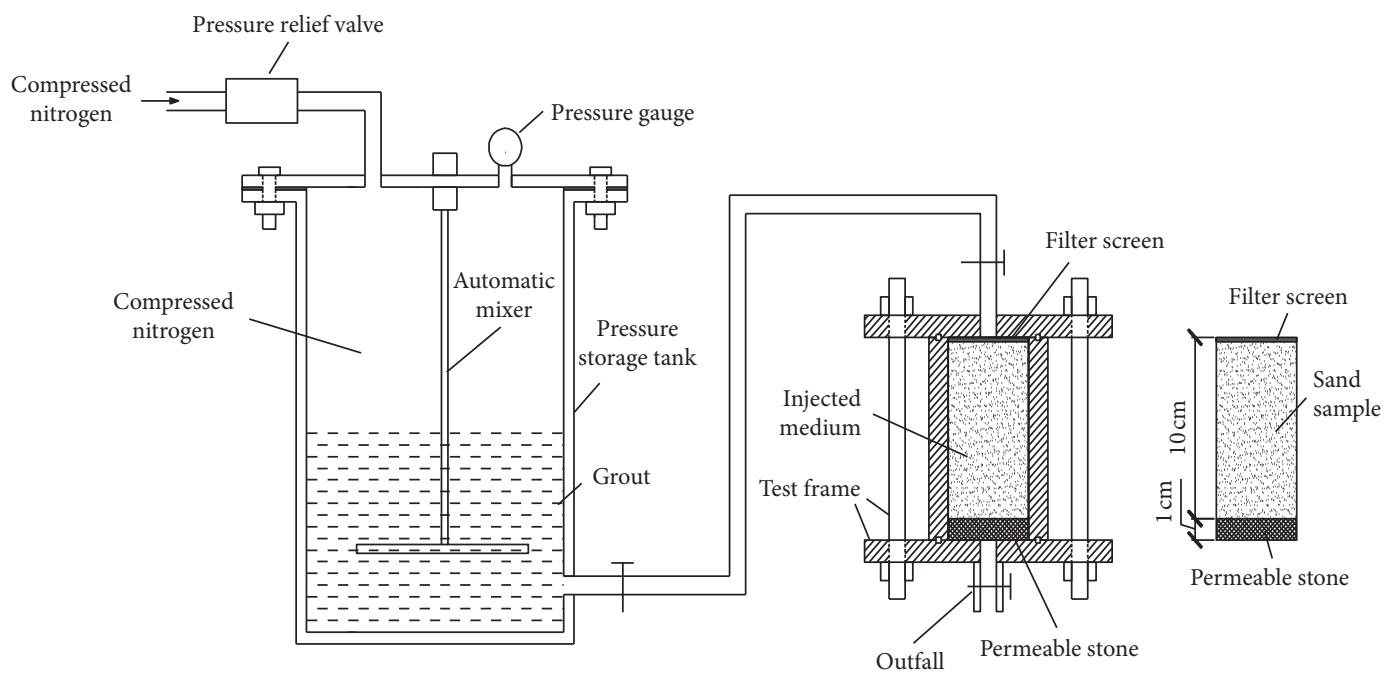

FIgURE 1: The test apparatus used in the sand penetration grouting simulation test.

TABLE 1: The chemical composition of the cement used in the tests.

\begin{tabular}{cccccccccc}
\hline Cement & $\mathrm{SiO}_{2}(\%)$ & $\mathrm{Fe}_{2} \mathrm{O}_{3}(\%)$ & $\mathrm{Al}_{2} \mathrm{O}_{3}(\%)$ & $\mathrm{CaO}(\%)$ & $\mathrm{MgO}(\%)$ & $\mathrm{SO}_{3}(\%)$ & $\mathrm{K}_{2} \mathrm{O}(\%)$ & $\mathrm{Na}_{2} \mathrm{O}(\%)$ & $\mathrm{O}(\mathrm{m}$ (\%) $(\%)$ \\
\hline PO.42.5 & 21.65 & 2.85 & 9.15 & 54.06 & 3.90 & 3.62 & 0.66 & 0.24 & 3.87 \\
\hline
\end{tabular}

TABLE 2: The basic physical and mechanical properties of the cement used in the tests.

\begin{tabular}{|c|c|c|c|c|c|}
\hline Cement & Specific surface area $\left(\mathrm{m}^{2} / \mathrm{kg}\right)$ & $\begin{array}{l}\text { Initial setting } \\
\text { time }(\mathrm{h})\end{array}$ & Finial setting time $(\mathrm{h})$ & $\begin{array}{c}3 \mathrm{~d} \\
\text { compressive strength }(\mathrm{MPa})\end{array}$ & $\begin{array}{c}28 \mathrm{~d} \\
\text { compressive strength (MPa) }\end{array}$ \\
\hline PO. 42.5 & 385 & 15.1 & 21.5 & 4 & 13 \\
\hline
\end{tabular}

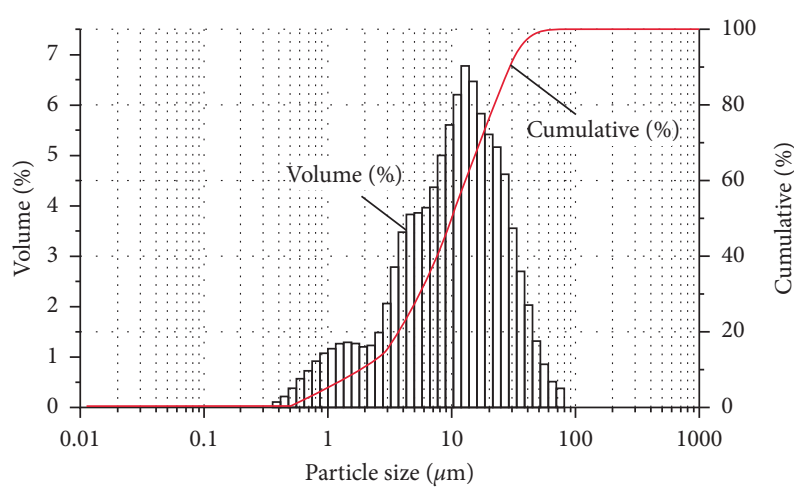

Figure 2: The grain-size distribution curve of cement.

TABLE 3: Characteristic particle size of cement used in the tests.

\begin{tabular}{lccc}
\hline Cement & $d_{85}(\mu \mathrm{m})$ & $d_{90}(\mu \mathrm{m})$ & $d_{95}(\mu \mathrm{m})$ \\
\hline PO.42.5 & 23.872 & 28.93 & 36.127 \\
\hline
\end{tabular}

$d_{85}, d_{90}$, and $d_{95}$ are particle diameters corresponding to $85 \%, 90 \%$, and $95 \%$ of the cement particle-size distribution curve, respectively.

the diffusion range of the grout and increases the reinforcement area but has no effect on the groutability of sand layer $[33,34]$. For the range of pressures considered in the study, only one typical value of grouting pressure $(1 \mathrm{MPa})$ is presented. And except for the sand particle size, the relative density of sand layer $D_{r}$, slurry water-cement ratio $W / C$, and clay content $\Omega$ are defined as independent variables. The relative density of sand layer varies within $0 \sim 100 \%$, the clay content within $0 \sim 12 \%$, and the slurry water-cement ratio within $0.8 \sim 2.0$.

The test plan is shown in Tables 5 and 6 . Table 5 is the test plan for sand layer groutability with the clay content being zero, and Table 6 is the test plan for sand layer groutability with varying clay content.

The specific experimental procedures of sand penetration grouting simulation test are as follows:

(1) Screen the quartz sand for the test, and prepare different types of sand samples with different particle size groups according to different proportions.

(2) According to different clay content, weigh different quality clay and test sand, mix and stir evenly.

(3) A permeable stone is placed at the bottom of the mold to restrict the overall movement of the sand sample and provide a drainage channel for free water during the grouting process (as shown in Figure 1). Then, the sand sample is divided into three equal layers and poured into the mold. Before placing the next layer, each layer is compacted with wood to achieve the required relative density. A filter screen is 
TABLE 4: The characteristic particle size and other physical parameters.

\begin{tabular}{|c|c|c|c|c|c|c|c|c|}
\hline Sample & Sand type & Particle size range $(\mathrm{mm})$ & $D_{15}(\mathrm{~mm})$ & $D_{10}(\mathrm{~mm})$ & $\rho_{\text {dmax }}\left(\mathrm{g} / \mathrm{cm}^{3}\right)$ & $\rho_{\mathrm{dmin}}\left(\mathrm{g} / \mathrm{cm}^{3}\right)$ & $e_{\min }$ & $e_{\max }$ \\
\hline 1 & Single particle size group & $0.08 \sim 0.16$ & 0.092 & 0.088 & 1.597 & 1.409 & 0.655 & 0.881 \\
\hline 2 & Single particle size group & $0.16 \sim 0.315$ & 0.183 & 0.1755 & 1.631 & 1.439 & 0.617 & 0.841 \\
\hline 3 & Single particle size group & $0.315 \sim 0.63$ & 0.362 & 0.347 & 1.671 & 1.489 & 0.578 & 0.780 \\
\hline 4 & Single particle size group & $0.63 \sim 1.25$ & 0.723 & 0.692 & 1.686 & 1.493 & 0.571 & 0.775 \\
\hline 5 & $\begin{array}{c}0.63 \sim 1.25 \mathrm{~mm}, 80 \% \\
1.25 \sim 2.5 \mathrm{~mm}, 20 \%\end{array}$ & $0.63 \sim 2.5$ & 0.746 & 0.708 & 1.689 & 1.499 & 0.567 & 0.771 \\
\hline 6 & $\begin{array}{c}0.63 \sim 1.25 \mathrm{~mm}, 60 \% \\
1.25 \sim 2.5 \mathrm{~mm}, 40 \%\end{array}$ & $0.63 \sim 2.5$ & 0.785 & 0.733 & 1.693 & 1.511 & 0.564 & 0.765 \\
\hline 7 & $\begin{array}{c}0.63 \sim 1.25 \mathrm{~mm}, 40 \% \\
1.25 \sim 2.5 \mathrm{~mm}, 60 \%\end{array}$ & $0.63 \sim 2.5$ & 0.863 & 0.785 & 1.698 & 1.517 & 0.561 & 0.761 \\
\hline 8 & $\begin{array}{c}0.63 \sim 1.25 \mathrm{~mm}, 20 \% \\
1.25 \sim 2.5 \mathrm{~mm}, 80 \%\end{array}$ & $0.63 \sim 2.5$ & 1.095 & 0.94 & 1.703 & 1.524 & 0.557 & 0.752 \\
\hline 9 & Single particle size group & $1.25 \sim 2.5$ & 1.438 & 1.375 & 1.706 & 1.539 & 0.554 & 0.748 \\
\hline 10 & Single particle size group & $2.5 \sim 5$ & 2.875 & 2.75 & 1.732 & 1.569 & 0.525 & 0.737 \\
\hline 11 & Single particle size group & $5 \sim 10$ & 5.75 & 5.5 & 1.766 & 1.597 & 0.498 & 0.711 \\
\hline
\end{tabular}

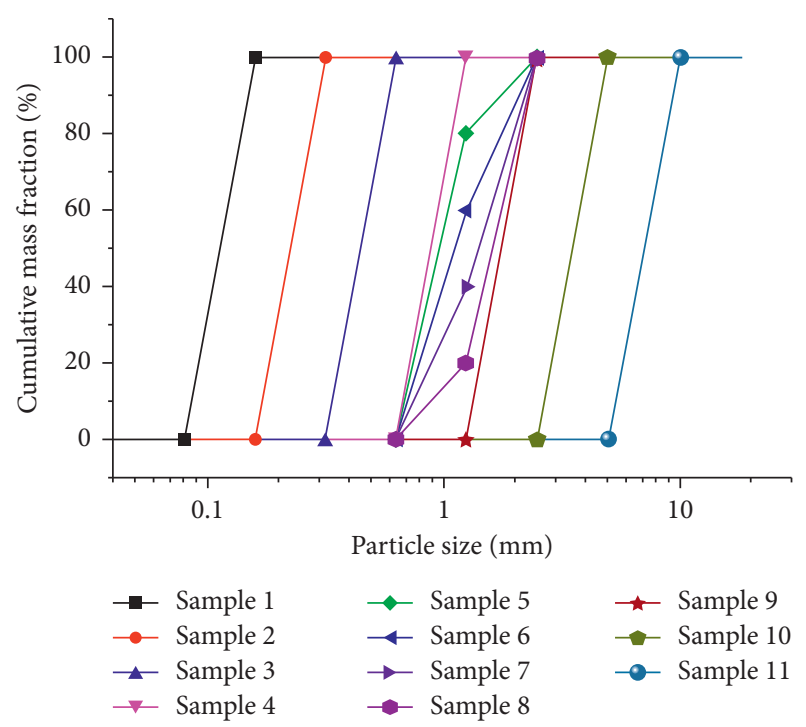

FIgURE 3: The grain-size distribution curve of the sand sample.

set on the top of the sand sample to prevent loosing sand particles from moving and reduce the impact of grout injection on the sand sample.

(4) Connect the grouting device, prepare the cement slurry, and start grouting. Keep the pressure constant $(1 \mathrm{MPa})$ during the grouting process, and when the grouting time is reached ( 5 minutes), disassemble the sample molds. Pay attention to the release of the internal pressure of the grouting barrel and the grouting pipeline before dismantling to prevent the residual pressure of the test from causing danger.

(5) Observe the internal penetration of the grouting sample and analyze the experimental results.

(6) Clean the grouting device. Change the test conditions and repeat the above test.

In order to facilitate readers to better understand this paper, a flowchart of the overall framework is shown in Figure 4.
TABLE 5: The test plan for sand layer groutability with clay content being zero.

\begin{tabular}{|c|c|c|c|c|}
\hline \multirow{2}{*}{ Type } & \multicolumn{3}{|c|}{ Sand characteristic } & \multirow{2}{*}{ Cement mixture } \\
\hline & $D_{15}(\mathrm{~mm})$ & $D_{r}(\%)$ & $\Omega(\%)$ & \\
\hline$T 1$ & 0.092 & 0 & 0 & $0.8,1.0,1.2,1.4,1.6,2.0$ \\
\hline$T 2$ & 0.183 & 0 & 0 & $0.8,1.0,1.2,1.4,1.6,2.0$ \\
\hline T3 & 0.362 & 0 & 0 & $0.8,1.0,1.2,1.4,1.6,2.0$ \\
\hline$T 4$ & 0.723 & 0 & 0 & $0.8,1.0,1.2,1.4,1.6,2.0$ \\
\hline T5 & 0.723 & 25 & 0 & $0.8,1.0,1.2,1.4,1.6,2.0$ \\
\hline T6 & 0.723 & 50 & 0 & $0.8,1.0,1.2,1.4,1.6,2.0$ \\
\hline$T 7$ & 0.723 & 75 & 0 & $0.8,1.0,1.2,1.4,1.6,2.0$ \\
\hline$T 8$ & 0.723 & 100 & 0 & $0.8,1.0,1.2,1.4,1.6,2.0$ \\
\hline$T 9$ & 0.746 & 0 & 0 & $0.8,1.0,1.2,1.4,1.6,2.0$ \\
\hline$T 10$ & 0.746 & 25 & 0 & $0.8,1.0,1.2,1.4,1.6,2.0$ \\
\hline$T 11$ & 0.746 & 50 & 0 & $0.8,1.0,1.2,1.4,1.6,2.0$ \\
\hline$T 12$ & 0.746 & 75 & 0 & $0.8,1.0,1.2,1.4,1.6,2.0$ \\
\hline$T 13$ & 0.746 & 100 & 0 & $0.8,1.0,1.2,1.4,1.6,2.0$ \\
\hline$T 14$ & 0.785 & 0 & 0 & $0.8,1.0,1.2,1.4,1.6,2.0$ \\
\hline$T 15$ & 0.785 & 25 & 0 & $0.8,1.0,1.2,1.4,1.6,2.0$ \\
\hline$T 16$ & 0.785 & 50 & 0 & $0.8,1.0,1.2,1.4,1.6,2.0$ \\
\hline$T 17$ & 0.785 & 75 & 0 & $0.8,1.0,1.2,1.4,1.6,2.0$ \\
\hline$T 18$ & 0.785 & 100 & 0 & $0.8,1.0,1.2,1.4,1.6,2.0$ \\
\hline$T 19$ & 0.863 & 0 & 0 & $0.8,1.0,1.2,1.4,1.6,2.0$ \\
\hline$T 20$ & 0.863 & 25 & 0 & $0.8,1.0,1.2,1.4,1.6,2.0$ \\
\hline$T 21$ & 0.863 & 50 & 0 & $0.8,1.0,1.2,1.4,1.6,2.0$ \\
\hline$T 22$ & 0.863 & 75 & 0 & $0.8,1.0,1.2,1.4,1.6,2.0$ \\
\hline$T 23$ & 0.863 & 100 & 0 & $0.8,1.0,1.2,1.4,1.6,2.0$ \\
\hline$T 24$ & 1.095 & 0 & 0 & $0.8,1.0,1.2,1.4,1.6,2.0$ \\
\hline$T 25$ & 1.095 & 25 & 0 & $0.8,1.0,1.2,1.4,1.6,2.0$ \\
\hline$T 26$ & 1.095 & 50 & 0 & $0.8,1.0,1.2,1.4,1.6,2.0$ \\
\hline$T 27$ & 1.095 & 75 & 0 & $0.8,1.0,1.2,1.4,1.6,2.0$ \\
\hline$T 28$ & 1.095 & 100 & 0 & $0.8,1.0,1.2,1.4,1.6,2.0$ \\
\hline$T 29$ & 1.438 & 100 & 0 & $0.8,1.0,1.2,1.4,1.6,2.0$ \\
\hline T30 & 2.875 & 100 & 0 & $0.8,1.0,1.2,1.4,1.6,2.0$ \\
\hline T31 & 5.75 & 100 & 0 & $0.8,1.0,1.2,1.4,1.6,2.0$ \\
\hline
\end{tabular}

\section{Results and Analysis of Groutability Test}

For successful grouting, the sand layer is filled with slurry, that is, the slurry can fill up the $10 \mathrm{~cm}$ sand column, and the 
TABLE 6: The test plan for sand layer groutability with varying clay content.

\begin{tabular}{|c|c|c|c|c|}
\hline \multirow{2}{*}{ Type } & \multicolumn{3}{|c|}{ Sand characteristic } & \multirow{2}{*}{ Cement mixture } \\
\hline & $D_{15}(\mathrm{~mm})$ & $D_{r}(\%)$ & $\Omega(\%)$ & \\
\hline TC1 & 0.723 & 0 & $0,4,8,12$ & 0.8 \\
\hline TC2 & 0.723 & 0 & $0,4,8,12$ & 1.0 \\
\hline TC3 & 0.723 & 0 & $0,4,8,12$ & 1.2 \\
\hline TC4 & 0.723 & 0 & $0,4,8,12$ & 1.4 \\
\hline TC5 & 0.723 & 0 & $0,4,8,12$ & 1.6 \\
\hline TC6 & 0.723 & 0 & $0,4,8,12$ & 2.0 \\
\hline TC7 & 0.723 & 50 & $0,4,8,12$ & 0.8 \\
\hline TC8 & 0.723 & 50 & $0,4,8,12$ & 1.0 \\
\hline TC9 & 0.723 & 50 & $0,4,8,12$ & 1.2 \\
\hline TC10 & 0.723 & 50 & $0,4,8,12$ & 1.4 \\
\hline TC11 & 0.723 & 50 & $0,4,8,12$ & 1.6 \\
\hline TC12 & 0.723 & 50 & $0,4,8,12$ & 2.0 \\
\hline TC13 & 0.723 & 100 & $0,4,8,12$ & 0.8 \\
\hline TC14 & 0.723 & 100 & $0,4,8,12$ & 1.0 \\
\hline TC15 & 0.723 & 100 & $0,4,8,12$ & 1.2 \\
\hline TC16 & 0.723 & 100 & $0,4,8,12$ & 1.4 \\
\hline TC17 & 0.723 & 100 & $0,4,8,12$ & 1.6 \\
\hline TC18 & 0.723 & 100 & $0,4,8,12$ & 2.0 \\
\hline TC19 & 0.785 & 0 & $0,4,8,12$ & 0.8 \\
\hline TC20 & 0.785 & 0 & $0,4,8,12$ & 1.0 \\
\hline TC21 & 0.785 & 0 & $0,4,8,12$ & 1.2 \\
\hline TC22 & 0.785 & 0 & $0,4,8,12$ & 1.4 \\
\hline TC23 & 0.785 & 0 & $0,4,8,12$ & 1.6 \\
\hline TC24 & 0.785 & 0 & $0,4,8,12$ & 2.0 \\
\hline TC25 & 0.785 & 50 & $0,4,8,12$ & 0.8 \\
\hline TC26 & 0.785 & 50 & $0,4,8,12$ & 1.0 \\
\hline TC27 & 0.785 & 50 & $0,4,8,12$ & 1.2 \\
\hline TC28 & 0.785 & 50 & $0,4,8,12$ & 1.4 \\
\hline TC29 & 0.785 & 50 & $0,4,8,12$ & 1.6 \\
\hline TC30 & 0.785 & 50 & $0,4,8,12$ & 2.0 \\
\hline TC31 & 0.785 & 100 & $0,4,8,12$ & 0.8 \\
\hline TC32 & 0.785 & 100 & $0,4,8,12$ & 1.0 \\
\hline TC33 & 0.785 & 100 & $0,4,8,12$ & 1.2 \\
\hline TC34 & 0.785 & 100 & $0,4,8,12$ & 1.4 \\
\hline TC35 & 0.785 & 100 & $0,4,8,12$ & 1.6 \\
\hline TC36 & 0.785 & 100 & $0,4,8,12$ & 2.0 \\
\hline
\end{tabular}

mixture of slurry and sand can be regarded as uniform. As for the insufficient grouting, the slurry can only be grouted at a certain depth in the sand column, and there is a clear interface between the sand layer grouted and the one not. In the unsuccessful grouting situations, the volume of the slurry entering the sand layer is negligible compared to the entire sand column.

The results of the sand layer groutability with the clay content being zero are shown in Figure 5, from which the following can be concluded:

(1) The particle size of the sand layer is positively related to its groutability. With the increase of the particle size of the sand layer, the corresponding grouting transfers from an unsuccessful one to an insufficient one and finally becomes a successful one. Under the most favorable conditions, where the slurry watercement ratio is 2.0 and the relative density is $0 \%$, the corresponding sand layer samples 1 3

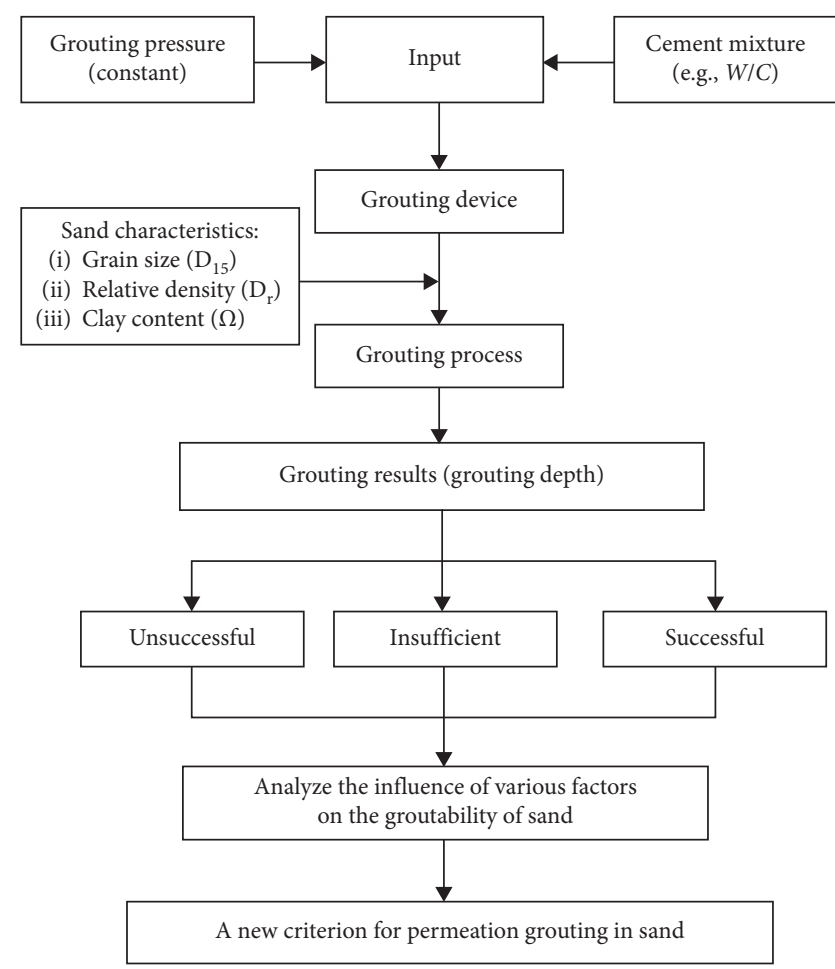

FIGURE 4: Flowchart of the overall framework.

$\left(D_{15}=0.092 \mathrm{~mm} \sim 0.362 \mathrm{~mm}\right)$ are all in unsuccessful grouting condition. Under the most unfavorable conditions, where the slurry water-cement ratio is 0.8 and relative density is $100 \%$, the corresponding sand layer samples 9 11 $\left(D_{15}=1.438 \mathrm{~mm} \sim 5.75 \mathrm{~mm}\right)$ are all in successful grouting condition. The transition from unsuccessful grouting to successful grouting occurs in the sand layer of samples $4 \sim 8$ $\left(D_{15}=0.723 \mathrm{~mm} \sim 1.095 \mathrm{~mm}\right)$. Therefore, the particle size of sand layer is the most important factor affecting the groutability of sand layer.

(2) The slurry water-cement ratio is positively related to the sand layer groutability. With the increase of $W / C$, the groutability of sand layer increases. For example, when $D_{15}=0.723 \mathrm{~mm}, D_{\mathrm{r}}=0 \%$, and the $W / C$ increases from 0.8 to 2.0; the insufficient grouting of the sand layer is changed into successful grouting.

(3) The relative density of sand layer $D_{r}$ is negatively related to the groutability of sand layer. With the increase of $D_{r}$, the groutability of the sand layer becomes lower.

The results regarding the groutability of the sand layer with varying clay content are shown in Figure 6.

We can see from Figure 6 that the clay content of the sand layer is negatively related to the groutability of the sand layer. Because clay will occupy part of the pore space of the sand layer, the porosity of the sand layer will be reduced, thus leading to lower groutability. With the increase of clay content, the sand layer goes through a transition from successful grouting to unsuccessful grouting. 


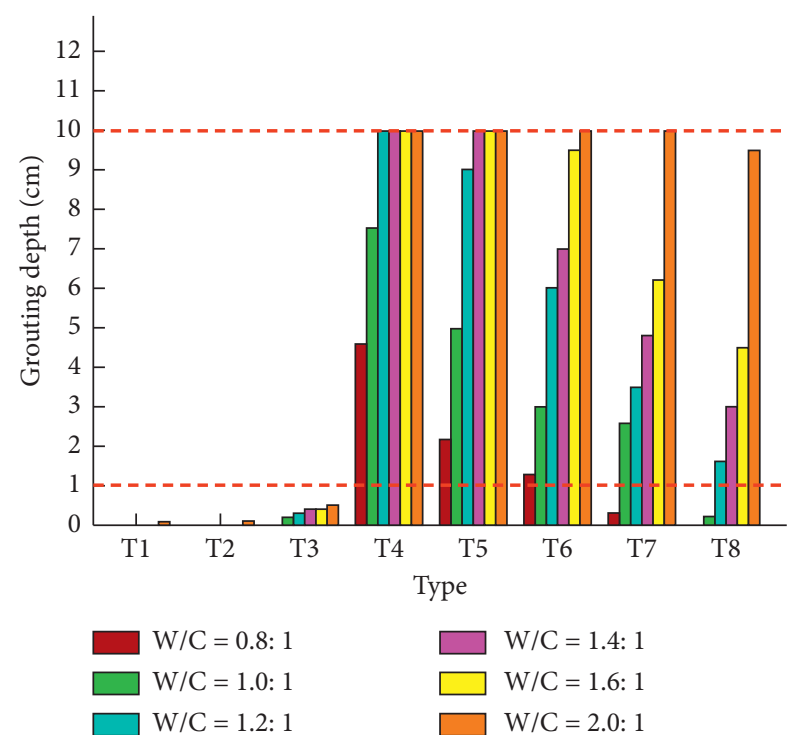

(a)

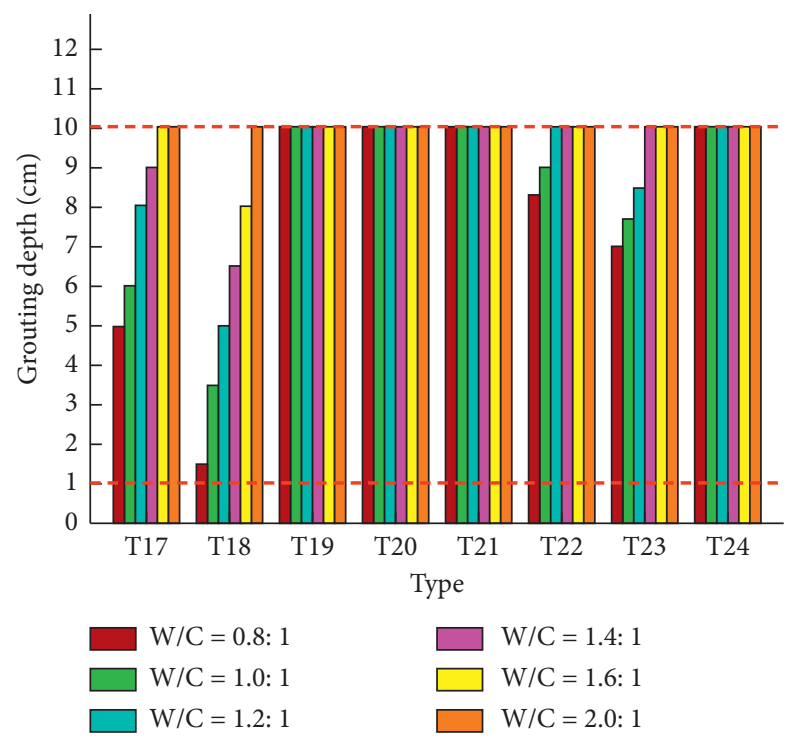

(c)

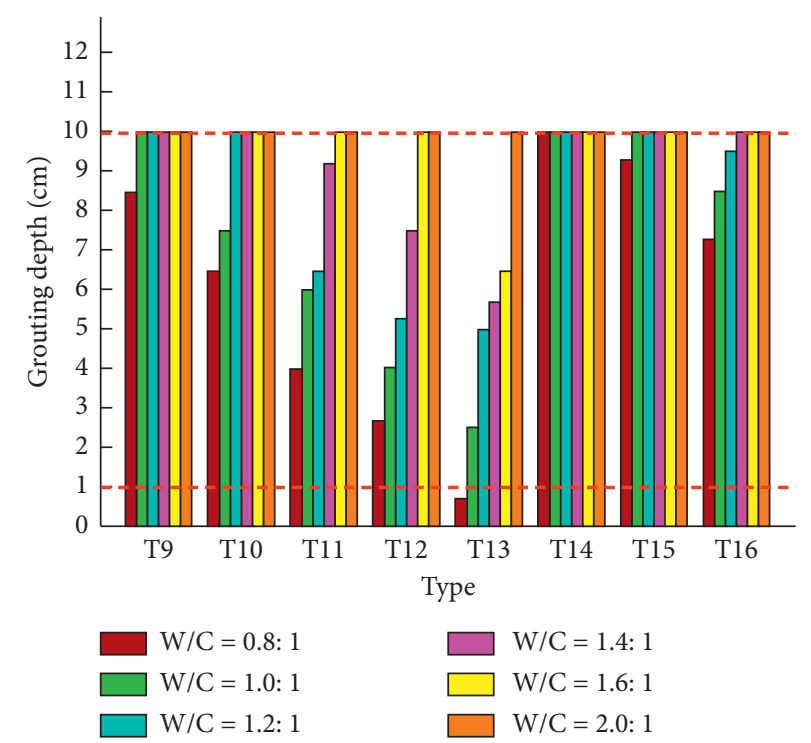

(b)

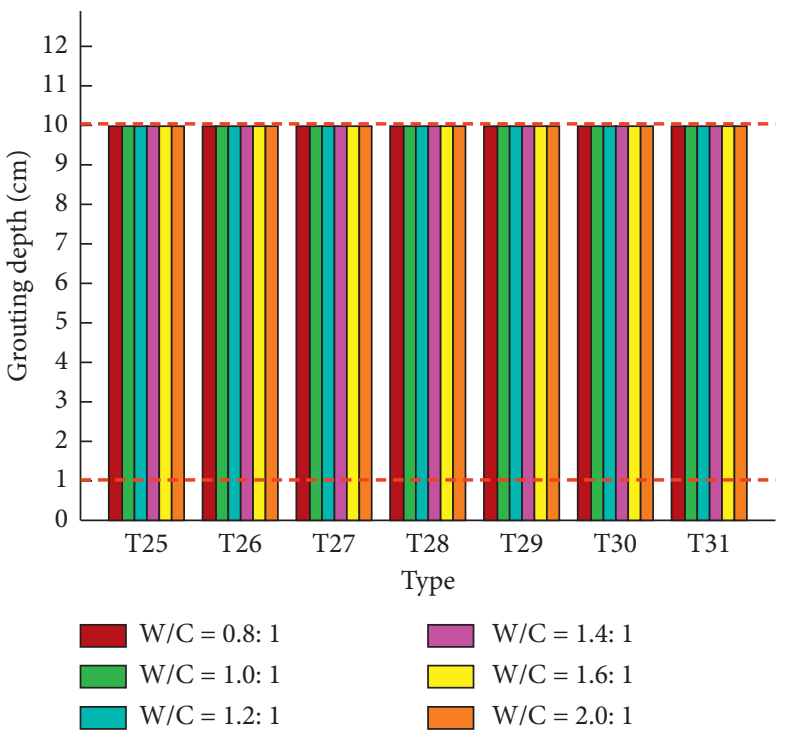

(d)

Figure 5: Results of the groutability test.

\section{A New Formula to Predict Groutability}

The essence of the sand layer groutability is the evaluation of the links between the pore size of the sand layer and the particle size of the slurry: the density and clay content of the sand layer influence the relevant groutability by directly affecting its pore size. The slurry water-cement ratio determines the reuniting effect of the particles in the slurry, which indirectly affects the particle size of the slurry. Then, the ratio of the characteristic particle size of the sand layer to the characteristic particle size of the slurry can still be used to reflect the groutability of sand layer. The index of the groutability of sand layer can be expressed as [25]

$$
N=\frac{D(\text { sand })}{d(\text { grout })}
$$

where $N$ is the index of the groutability of the sand layer, $D$ (sand) is the characteristic particle size of the sand layer, and $d$ (grout) is the characteristic particle size of the slurry.

Therefore, the different densities and clay contents of the sand layer can be seen as a correction for the pore size of the sand layer, and the water-cement ratio of the slurry can be seen as a correction for the particle size of the slurry. The characteristic particle size of sand layer is expressed as $D_{15}$, and the characteristic particle size of slurry is expressed as $d_{85}[35,36]$. Hence, the index of the groutability of sand layer can be expressed as

$$
N=\frac{K_{1} K_{2} D_{15}}{K_{3} d_{85}},
$$

where $K_{1}$ is the correction coefficient of sand layer density to sand characteristic particle size, $K_{2}$ is the correction 


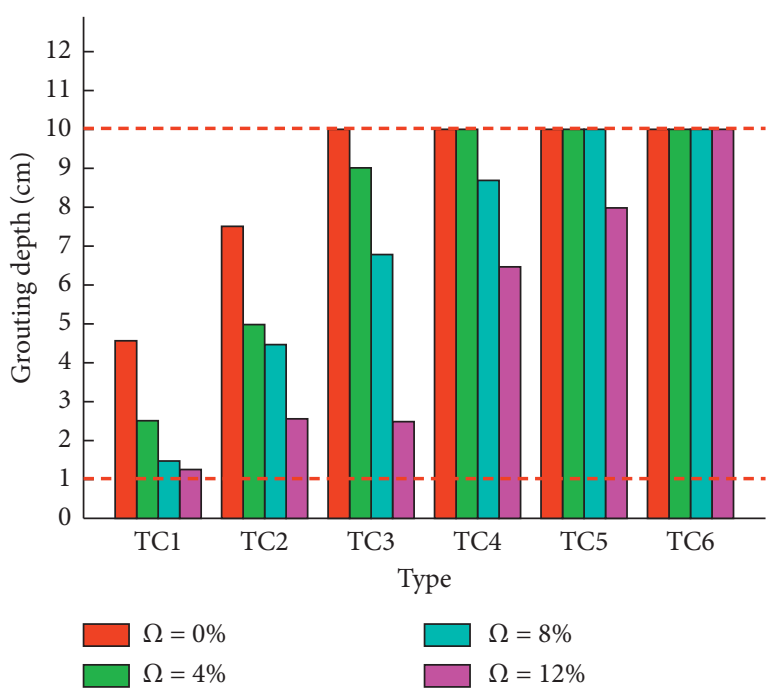

(a)

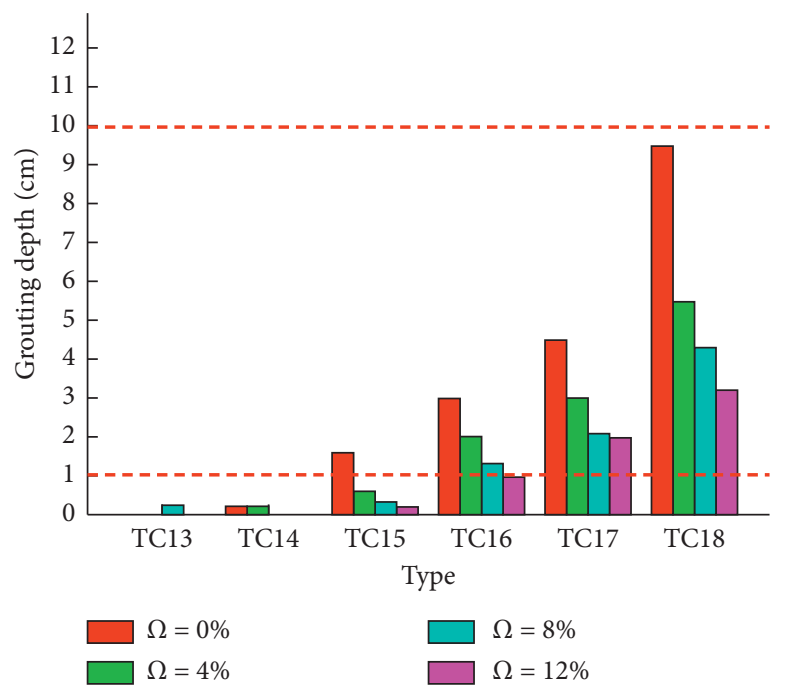

(c)

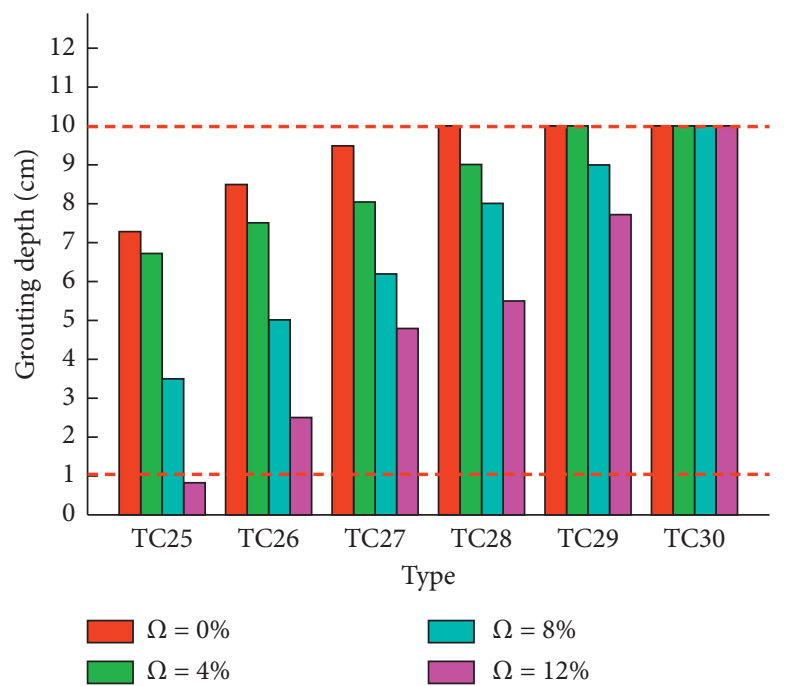

(e)

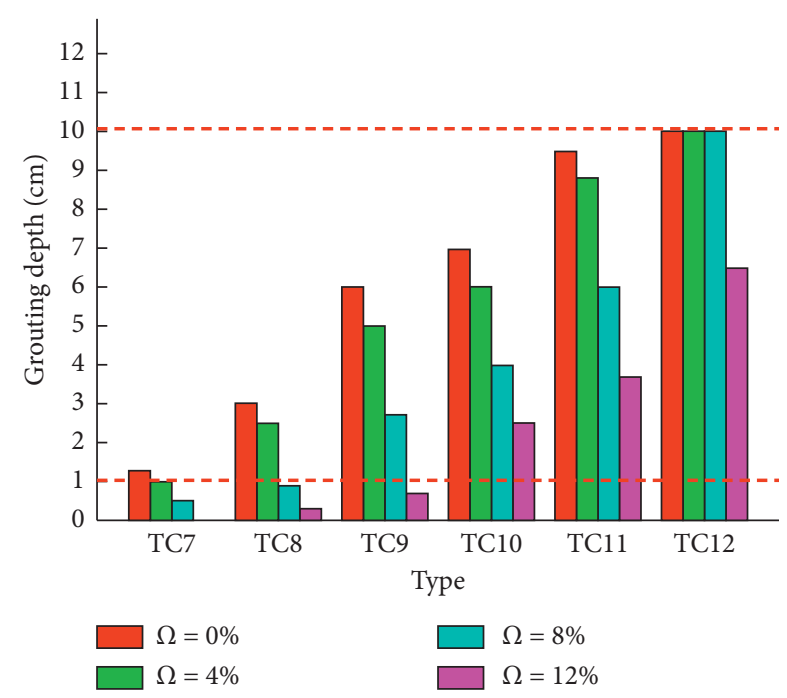

(b)

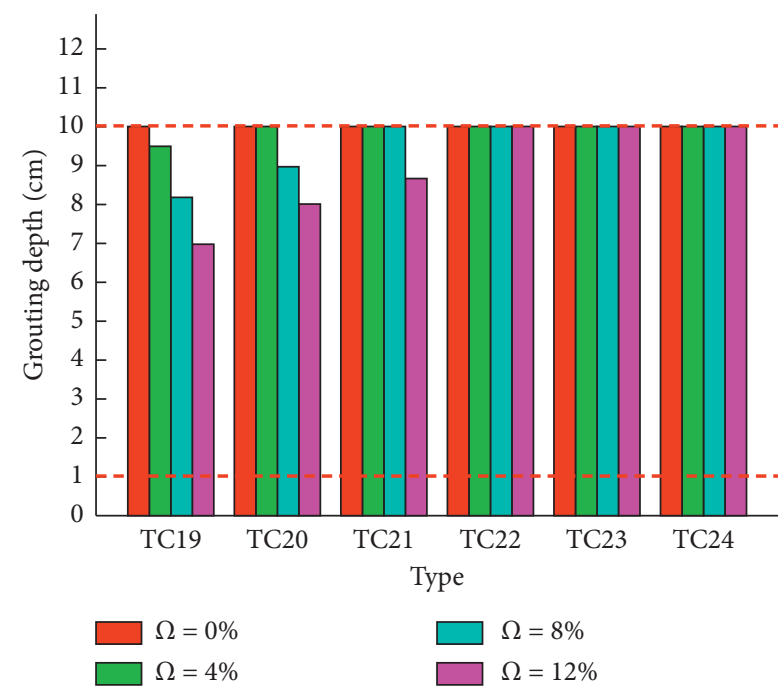

(d)

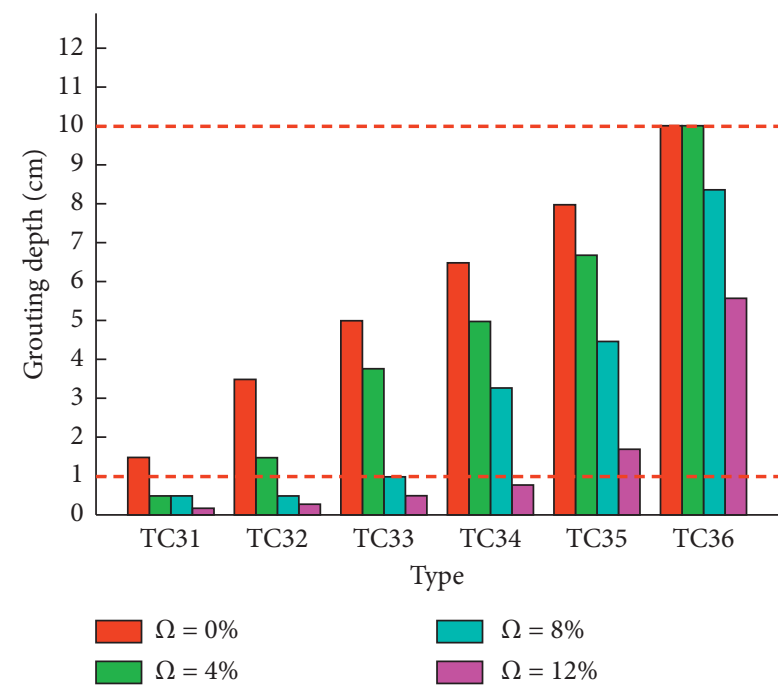

(f)

FIGURE 6: Results of the groutability of the sand layer with varying clay content. 


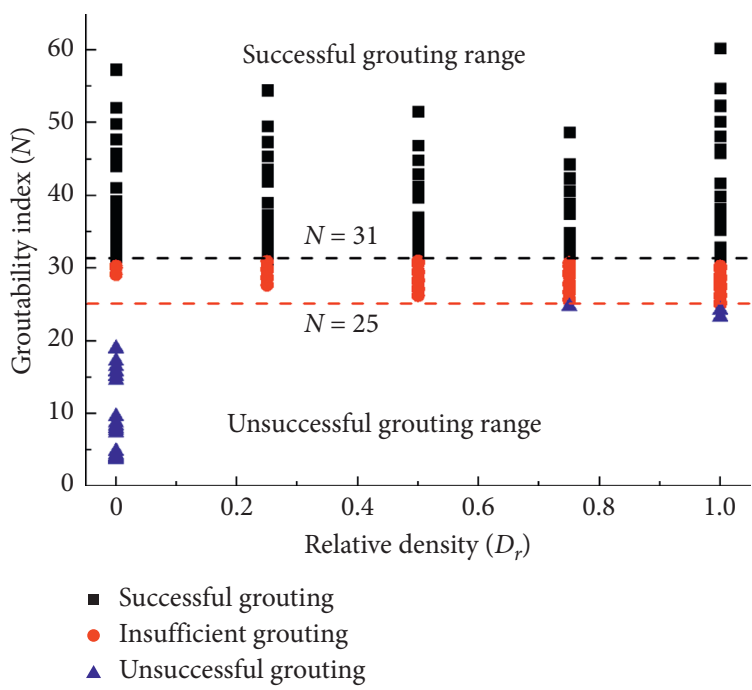

Figure 7: The relation between the groutability index $N$ and the groutability of sand layer.

coefficient of clay content to sand characteristic particle size, and $K_{3}$ is the correction coefficient of slurry water-cement ratio to slurry particle size.

Through the statistical analysis of sand layer permeability data, the correction coefficients $K_{1}, K_{2}$, and $K_{3}$ can be expressed by linear fitting:

$$
\left\{\begin{array}{l}
K_{1}=1-0.2 D_{r}, \\
K_{2}=1-1.1 \Omega, \\
K_{3}=1.2-\frac{0.2 W}{C} .
\end{array}\right.
$$

The $N$ in each condition is shown in Tables 5 and 6. By analyzing Figure 7 , we can get the relation between the groutability index $N$ and the groutability of sand layer:

$$
\left\{\begin{array}{l}
\text { If } \quad N>31 \text {, successful grouting, } \\
\text { If } 25 \leq N \leq 31 \text {, insufficient grouting, } \\
\text { If } \quad N<25 \text {, unsuccessful grouting. }
\end{array}\right.
$$

Equation (4) is the occurrence criterion for determining different penetration and reinforcement modes of permeation grouting, if $N$ is not less than 25, the strengthening mode of permeation diffusion will appear during the sand grouting process.

\section{Engineering Guidance}

A certain area of a tunnel goes through the sand layer with clay, so gushing water and sand inrush can take place easily due to the complexity of geological conditions. In order to solve the difficult problem of the project, grouting is used for treatment and reinforcement. For sand grouting, it is necessary to consider the feasibility of grouting reinforcement and the underlying grouting diffusion reinforcement mode, so as to provide reasonable guidance for the project.

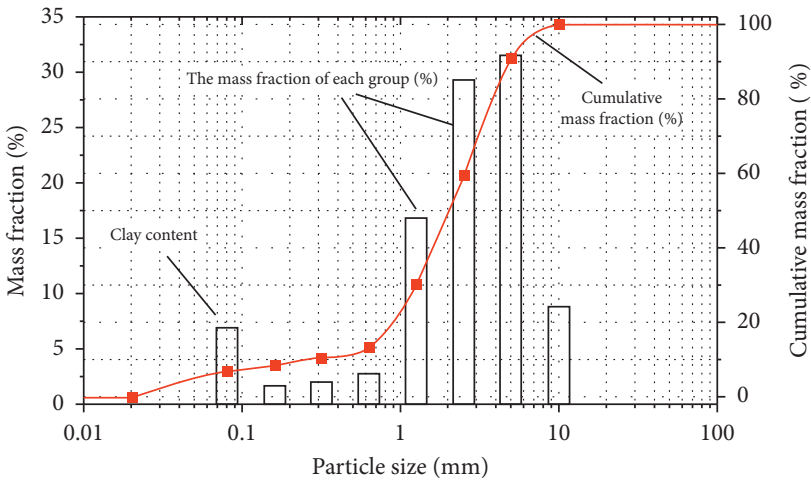

FIgURE 8: The sand grain-size distribution curve in a certain area of a tunnel.

Through applying the results of this study and analyzing the corresponding groutability, it can be preliminarily determined whether the permeation grouting reinforcement mode will appear or not, so as to facilitate further construction.

The measured moisture content $\omega$ of the clay sand sample in this tunnel is $15.8 \%$, the clay content $\Omega=6.91 \%$, the dominant diameter $d_{60}=2.63 \mathrm{~mm}$, the effective size $d_{10}=0.25 \mathrm{~mm}, d_{30}=1.29 \mathrm{~mm}$, the nonuniform coefficient $\mathrm{C}_{\mathrm{u}}=10.5$, and the coefficient of uniformity $\mathrm{C}_{\mathrm{c}}=2.53$, which is fine-grained soil sand with good gradation, and the grainsize distribution curve is shown in Figure 8. From the sand grain-size distribution curve, we can get $D_{15}=0.72 \mathrm{~mm}$.

Because it cannot be measured on the field, it is approximately considered that the sand layer before the inrush of sand is of medium density, relative density $D_{r}=50 \%$. The ordinary Portland cement slurry is used for calculating the groutability, the range of water-cement ratio is $0.8 \sim 2.0$, and the characteristic particle size of cement slurry $d_{85}$ is $23.872 \mu \mathrm{m}$. Based on equations (2) and (3), we can get the groutability index of sand layer $N$ corresponding to different water-cement ratios of the slurry. The calculation results are shown in Table 7. 
TABLE 7: Calculation results of the sand layer groutability.

\begin{tabular}{|c|c|c|c|c|c|}
\hline $\begin{array}{l}\text { Slurry water-cement ratio } \\
W / C\end{array}$ & $\begin{array}{c}\text { Correction } \\
\text { coefficient } K_{1}\end{array}$ & $\begin{array}{c}\text { Correction } \\
\text { coefficient } K_{2}\end{array}$ & $\begin{array}{c}\text { Correction coefficient } \\
K_{3}\end{array}$ & $\begin{array}{c}\text { Groutability index of sand } \\
\text { layer } N\end{array}$ & Grouting \\
\hline 0.8 & 0.9 & 0.924 & 1.04 & 24.12 & $\begin{array}{l}\text { Unsuccessful } \\
\text { grouting }\end{array}$ \\
\hline 1.0 & & & 1 & 25.08 & Insufficient grouting \\
\hline 1.2 & & & 0.96 & 26.13 & Insufficient grouting \\
\hline 1.4 & & & 0.92 & 27.26 & Insufficient grouting \\
\hline 1.6 & & & 0.88 & 28.50 & Insufficient grouting \\
\hline 2.0 & & & 0.8 & 31.35 & Successful grouting \\
\hline
\end{tabular}

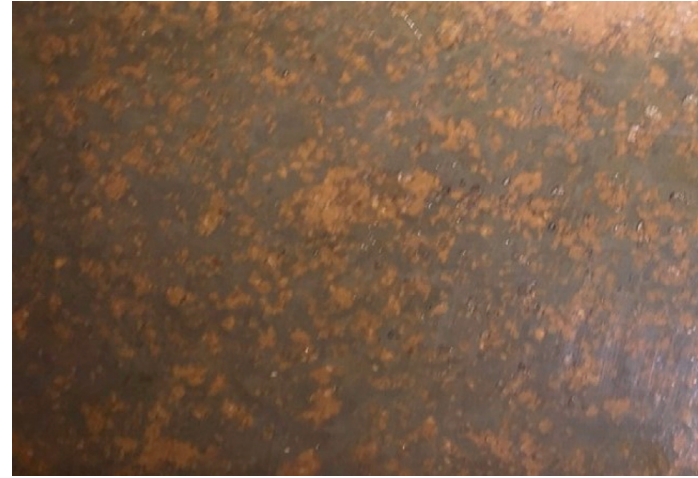

FIGURE 9: Sand layer penetration grouting.

As can be seen from Table 7 , for the ordinary cement slurry with different water-cement ratios, only when the water-cement ratio is 2.0, the groutability index of sand layer $N$ is greater than 31, and the grouting of the sand layer is a successful one, that is, the sand grouting diffusion reinforcement mode is permeation grouting mode, and the cement grout with water-cement ratio of 2.0 can be considered for grouting reinforcement. Figure 9 shows the sand layer treatment area after grouting reinforcement, in which the grout penetrated and filled well and is in a stable state after treatment, achieving the expected reinforcement purpose, which further proves the applicability of the formula.

\section{Conclusions}

In the present paper, the permeability of the ordinary Portland cement to sand layer is studied by means of a permeation grouting test apparatus, and the effects of the sand particle size, the relative density, the slurry water-cement ratio, and the clay content on the groutability of sand layer are analyzed. The following points can be concluded from the present investigation:

(1) The results show that the sand particle size and slurry water-cement ratio are positively related to the groutability of the sand layer, and the relative density and clay content of the sand layer are negatively related to the groutability of the sand layer. The sand particle size is the most important factor affecting the groutability of the sand layer, and the decrease of the sand particle size can lead to unsuccessful grouting. With the increase of sand particle size and slurry water-cement ratio, the groutability of sand layer is increased, which changes from unsuccessful grouting to insufficient grouting and finally becomes successful grouting. However, with the increase of the relative density and clay content, the groutability of the sand layer becomes lower.

(2) The essence of the sand layer groutability is the evaluation of the links between the pore size of the sand layer and the particle size of the slurry. In this paper, the index of the groutability of sand layer $N$ depends on the characteristic particle size of sand layer $D_{15}$, the characteristic particle size of slurry $d_{85}$, the relative density of sand layer $D_{r}$, clay content $\Omega$, and slurry water-cement ratio $W / C$. On this basis, an alternative empirical formula to estimate the groutability of sand layer is proposed, where the relation between the groutability index $N$ and the groutability of sand layer is obtained. It is also found that the permeation grouting mode will appear in the sand grouting process if $N$ is no less than 25 .

(3) The excavation of the vein after grouting reinforcement further proves the effectiveness of the formula. It is recommended to analyze the grouting diffusion reinforcement model before grouting onsite to guide the grouting design more reasonably.

\section{Data Availability}

The data used to support the findings of this study are available from the corresponding author upon request.

\section{Conflicts of Interest}

The authors declare that they have no conflicts of interest.

\section{Acknowledgments}

This work was supported by the General Program of National Natural Science Foundation of China (grant no. 51779133); the Joint Funds of National Natural Science Foundation of China (grant no. U1706223); and the China Scholarship Council (file number 201906220133).

\section{References}

[1] K. Hashimoto, S. Nishihara, S. Oji et al., "Field testing of permeation grouting using microfine cement," Proceedings of the Institution of Civil Engineers-Ground Improvement, vol. 169, no. 2, pp. 134-142, 2016. 
[2] Y. Gamil, I. Bakar, and K. Ahmed, "Simulation and development of instrumental setup to be used for cement grouting of sand soil," Emerging Science Journal, vol. 1, no. 1, pp. 16-27, 2017.

[3] Y. K. Qiao, F. L. Peng, and Y. Wang, "Monetary valuation of urban underground space: a critical issue for the decisionmaking of urban underground space development," Land Use Policy, vol. 69, pp. 12-24, 2017.

[4] Y. K. Qiao, F. L. Peng, S. Sabri, and A. Rajabifard, "Socioenvironmental costs of underground space use for urban sustainability," Sustainable Cities and Society, vol. 51, Article ID 101757, 2019.

[5] F. L. Peng, Y. K. Qiao, J. W. Zhao, K. Liu, and J.-C. Li, "Planning and implementation of underground space in Chinese central business district (CBD): a case of Shanghai Hongqiao CBD," Tunnelling and Underground Space Technology, vol. 95, Article ID 103176, 2020.

[6] S. L. Shen, P. G. A. Njock, A. Zhou, and H. M. Lyu, "Dynamic prediction of jet grouted column diameter in soft soil using Bi-LSTM deep learning," Acta Geotechnica, vol. 16, pp. 303315, 2021.

[7] I. Ivanova, S. Nefedov, A. Pustovgar, A. Adamtsevich, and A. Eremin, "Comparison of laboratory methods for the design of injection grouts based on microfine cements," Procedia Engineering, vol. 165, pp. 1536-1541, 2016.

[8] R. A. Mozumder, A. I. Laskar, and M. Hussain, "Penetrability prediction of microfine cement grout in granular soil using artificial intelligence techniques," Tunnelling and Underground Space Technology, vol. 72, pp. 131-144, 2018.

[9] S. G. Li, Research on Permeation Grouting Experiment and Application in Sandy Strata, Northeastern University, Shenyang, China, (in Chinese), 2010.

[10] G. Y. Ma and X. S. Lin, Water and Hydropower Engineering Grouting and Groundwater Drainage, China Water \& Power Press, Beijing, China, (in Chinese), 2001.

[11] C. Kutzner, Grouting of Rock and Soil, CRC Press, Boca Raton, FL, USA, 2020.

[12] M. Mollamahmutoğlu and E. Avci, "Evaluation of the validity of groutability prediction formulas by means of superfine cement grouts," Geotechnical and Geological Engineering, vol. 37, no. 5, pp. 3925-3936, 2019.

[13] E. Tekin, Experimental Studies on the Groutability of Microfine Cement (Rheocem 900) Grouts to Sands Having Various Gradations, Gazi University, Ankara, Turkey, 2004.

[14] E. Tekin and S. O. Akbas, "Artificial neural networks approach for estimating the groutability of granular soils with cementbased grouts," Bulletin of Engineering Geology and the Environment, vol. 70, no. 1, pp. 153-161, 2011.

[15] M. Mollamahmutoglu and E. Avci, "Ultrafine Portland cement grouting performance with or without additives," KSCE Journal of Civil Engineering, vol. 19, no. 7, pp. 2041-2050, 2015.

[16] M. Mollamahmutoglu and E. Avci, "Effectiveness of microfine Portland cement grouting on the strength and permeability of medium to fine sands," Periodica Polytechnica Civil Engineering, vol. 59, no. 3, pp. 319-326, 2015.

[17] I. N. Markou, D. N. Christodoulou, and D. K. Atmatzidis, "Effect of sand gradation on the groutability of cement suspensions," in Proceedings of the fourth international conference on grouting and deep mixing, pp. 2003-2012, New Orleans, LA, USA, August 2012.

[18] I. N. Markou, D. N. Christodoulou, E. S. Petala, and D. K. Atmatzidis, "Injectability of microfine cement grouts into limestone sands with different gradations: experimental investigation and prediction," Geotechnical and Geological Engineering, vol. 36, no. 2, pp. 959-981, 2018.

[19] H. G. Ozgurel and C. Vipulanandan, "Effect of fines content on the mechanical behavior and groutability of acrylamide grouted sands," Journal of Geotechnical and Geoenvironmental Engineering, vol. 131, no. 12, p. 1457, 2005.

[20] M. Hassanlourad and A. Sarrafi, "Investigation of sandy soils grouting-ability with sodium silicate chemically grout," Amirkabir Journal of Science \& Research (Civil \& Environmental Engineering), vol. 45, no. 2, pp. 41-48, 2014.

[21] S. L. Shen, Z. F. Wang, and W. C. Cheng, "Estimation of lateral displacement induced by jet grouting in clayey soils," Géotechnique, vol. 67, no. 7, pp. 621-630, 2017.

[22] Z. F. Wang, S. L. Shen, and G. Modoni, "Enhancing discharge of spoil to mitigate disturbance induced by horizontal jet grouting in clayey soil: theoretical model and application," Computers and Geotechnics, vol. 111, pp. 222-228, 2019.

[23] Z. F. Wang, S. L. Shen, G. Modoni, and A. Zhou, "Excess pore water pressure caused by the installation of jet grouting columns in clay," Computers and Geotechnics, vol. 125, Article ID 103667, 2020.

[24] R. W. Henn and N. C. Soule, "Ultrafine Cement in Pressure Grouting," American Society of Civil Engineers, Reston, VA, USA, 2010.

[25] E. B. Burwell, "Cement and clay grouting of foundations: practice of the corps of engineering," Journal of the Soil Mechanics and Foundations Division, vol. 84, no. 1, pp. 1-22, 1958.

[26] F. G. Bell, Engineering Treatment of Soils, CRC Press, Boca Raton, FL, USA, 1993.

[27] M. R. Azadi, A. Taghichian, and A. Taheri, "Optimization of cement-based grouts using chemical additives," Journal of Rock Mechanics and Geotechnical Engineering, vol. 9, no. 4, pp. 623-637, 2017.

[28] J. Herndon and T. Lenahan, Grouting in Soils, 1976.

[29] J. K. Mitchell, In-Place Treatment of Foundation soils, Vol. 96, Department of Civil Engineering, University of California, Berkeley, CA, USA, 1970.

[30] J. C. King and E. G. W. Bush, "Symposium on grouting: grouting of granular materials," Transactions of the American Society of Civil Engineers, vol. 128, no. 1, pp. 1279-1309, 1963.

[31] Z. P. Li, L. Z. Zhang, Y. T. Chu, and Q. S. Zhang, "Research on influence of water-cement ratio on reinforcement effect for permeation grouting in sand layer," Advances in Materials Science and Engineering, vol. 2020, Article ID 5329627, 12 pages, 2020.

[32] R. T. Liu, C. Y. Zhang, H. J. Liu, Y. Pei, X. H. Li, and Z. J. Wang, "Effects of flocculation of cement slurry on groutability of porous media," Construction and Building Materials, vol. 237, Article ID 117649, 2020.

[33] P. Yang, Z. B. Peng, Y. Q. Tang, W. X. Peng, and Z. M. He, "Penetration grouting reinforcement of sandy gravel," Journal of Central South University of Technology, vol. 15, no. 2, pp. 280-284, 2008.

[34] U. Mutman and A. Kavak, "Improvement of granular soils by low pressure grouting," International Journal of Physical Sciences, vol. 6, no. 17, pp. 4311-4322, 2011.

[35] J. K. Mitchell, Soil Improvement-State Of The Art Report, Vol. 4, Professor and Chairman of Civil Engineering, University of California, Berkeley, CA, USA, 1981.

[36] K. S. Keong, Properties of Cement Based Permeation Grout Used in Ground Engineering, National University of Singapore, Singapore, 2006. 